\title{
Why Aren't More Primary Care Residents Going into Primary Care? A Qualitative Study
}

\author{
Theodore Long, MD MHS ${ }^{1,2}$, Krisda Chaiyachati, MD MPH'2, Olatunde Bosu, MD³, Sohini Sircart, \\ Bradley Richards, $M D^{2}$, Megha Garg, $M D^{5}$, Kelly McGarry, MD , Sonja Solomon, $M D^{6}$, \\ Rebecca Berman, MD', Leslie Curry, PhD MPH ${ }^{1,2,4}$, John Moriarty, MD' ${ }^{2}$, and Stephen Huot, MD PhD ${ }^{2}$
}

'Robert Wood Johnson Clinical Scholars Program, Yale School of Medicine, New Haven, CT, USA; '² Department of Internal Medicine, Yale School of Medicine, New Haven, CT, USA; ${ }^{3}$ Yale School of Medicine, New Haven, CT, USA; ${ }^{4}$ Yale School of Public Health, New Haven, CT, USA; ${ }^{5}$ Department of Internal Medicine, Medical School of Brown University, Providence, RI, USA; 'Division of General Internal Medicine \& Primary Care, Brigham and Women's Hospital, Boston, MA, USA.

BACKGROUND: Workforce projections indicate a potential shortage of up to 31,000 adult primary care providers by the year 2025. Approximately $80 \%$ of internal medicine residents and nearly two-thirds of primary care internal medicine residents do not plan to have a career in primary care or general internal medicine.

OBJECTIVE: We aimed to explore contextual and programmatic factors within primary care residency training environments that may influence career choices.

DESIGN: This was a qualitative study based on semistructured, in-person interviews.

PARTICIPANTS: Three primary care internal medicine residency programs were purposefully selected to represent a diversity of training environments. Second and third year residents were interviewed.

APPROACH: We used a survey guide developed from pilot interviews and existing literature. Three members of the research team independently coded the transcripts and developed the code structure based on the constant comparative method. The research team identified emerging themes and refined codes. ATLAS.ti was used for the analysis.

KEY RESULTS: We completed 24 interviews (12 secondyear residents, and 12 third-year residents). The age range was 27-39 years. Four recurrent themes characterized contextual and programmatic factors contributing to residents' decision-making: resident expectations of a career in primary care, navigation of the boundary between social needs and medical needs, mentorship and perceptions of primary care, and structural features of the training program.

CONCLUSIONS: Addressing aspects of training that may discourage residents from careers in primary care such as lack of diversity in outpatient experiences and resident frustration with their inability to address social needs of patients, and strengthening aspects of training that may encourage interests in careers in primary care such as mentorship and protected time away from inpatient

Electronic supplementary material The online version of this article (doi:10.1007/s11606-016-3825-9) contains supplementary material, which is available to authorized users.

Received January 25, 2016

Revised May 25, 2016

Accepted July 14, 2016

Published online August 3, 2016 responsibilities during primary care rotations, may increase the proportion of residents enrolled in primary care training programs who pursue a career in primary care.

KEY WORDS: Primary care; Workforce; Meducation; Qualitative research. J Gen Intern Med 31(12): 1452-9

DOI: $10.1007 /$ s11606-016-3825-9

(C) Society of General Internal Medicine 2016

\section{INTRODUCTION}

The US healthcare system faces a shortage of up to 31,000 adult care generalists by the year 2025. ${ }^{1}$ Despite this looming deficit, approximately $80 \%$ of internal medicine residents, including nearly two-thirds of primary care internal medicine residents, do not plan to have a career in primary care or general internal medicine. ${ }^{2}$ Though there have been some slight improvements in primary care retention, it is now critically important to understand why primary care residents in particular are choosing not to enter the primary care workforce in order to inform changes, either to training programs or to real-world practice, that will help retain them in primary care.

Factors that contribute to residents choosing primary care versus subspecialty practice are not well understood. Studies have examined individual factors such as the relationship between indebtedness and specialty consideration, ${ }^{3-6}$ and resident satisfaction during and after residency. ${ }^{7,8}$ Recent evidence has found that the quality of continuity clinic experience is related to internal medicine resident satisfaction, ${ }^{9}$ and that training models with blocks of protected outpatient time that are separate from inpatient responsibilities may also increase resident satisfaction with their primary care rotations. ${ }^{10}$ In addition, the outpatient clinic experiences of residents may be associated with retained interest in primary care careers, ${ }^{11}$ though the influence of various factors may also differ by year of training and may be influenced by other experiences prior to residency. ${ }^{12,13}$ However, these studies have focused on specific factors, such as residency training satisfaction, and there is a need to understand holistically how the diverse experiences of trainees impact the decision to pursue primary care or another 
specialty, which can elucidate the complex and interdependent contributions of these factors. ${ }^{14}$

We sought to understand programmatic and contextual factors that influence career trajectories among primary care internal medicine residents, with a particular interest in potentially modifiable factors. Because little is known about which additional factors, particularly at the programmatic level, may be relevant to resident decision making, and because such factors may be complex and nuanced, we employed an exploratory approach through the use of qualitative methodology.

\section{METHODS}

\section{Study Design}

We conducted a multi-site, qualitative study with semistructured interviews. Grounded theory was chosen as the research method for this study, as it allowed for the construction of theory regarding the substantive area of primary care career interest and attrition through analysis of rich data from diverse study participants. ${ }^{15,16}$ The purpose of the grounded theory approach was to identify domains and constructs in the theory, but not mechanisms. Our approach is based upon sociological theory of career decision making, which includes three dimensions of the decision-making process: rational decision making, interaction with others in the specified training field, and the location of decisions within the context of turning points and routines. ${ }^{17}$

We used a purposeful sample of three primary care internal medicine programs. We chose to focus on primary care internal medicine programs as opposed to other traditional or categorical internal medicine programs, as residents in these programs had indicated an interest in primary care, given that they chose to enter a primary care training program. Eleven programs were considered for inclusion, and a sample of three was selected that represented a diversity of program characteristics potentially salient to the experience of residents: location at an academic medical center versus a community hospital, ambulatory scheduling structures, and percentage of graduates retained in primary care. The first two characteristics were applied to the 11 programs, and data was then collected on the percentage of graduates retained in primary care for three programs with variation in the location at a community hospital and ambulatory scheduling structures. The three sites were confirmed after variation across all three characteristics was confirmed (Table 1).

To assess retention of graduates in primary care, we solicited a residency program director at each site to provide a list of primary care resident graduates from 2012 to 2014 with their current job description and location. We chose 2012-2014, as these years most closely represent the program environment that the study participants experienced during residency. "Full-time primary care" was defined as full-time clinical practice without known extra-clinical responsibilities.
Table 1 Characteristics of Programs (2012-2014)

\begin{tabular}{|c|c|c|c|}
\hline & Site $1(n=27)$ & Site $2(n=43)$ & Site $3(n=27)$ \\
\hline \multicolumn{4}{|c|}{ Retention in Primary Care } \\
\hline $\begin{array}{l}\text { Full-time } \\
\text { primary care }\end{array}$ & $15 \%$ & $23 \%$ & $48 \%$ \\
\hline $\begin{array}{l}\text { Primary } \\
\text { care- related }\end{array}$ & $67 \%$ & $32 \%$ & $33 \%$ \\
\hline $\begin{array}{l}\text { Non- } \\
\text { primary care }\end{array}$ & $18 \%$ & $45 \%$ & $19 \%$ \\
\hline \multicolumn{4}{|c|}{ Structural Features of Training Program } \\
\hline $\begin{array}{l}\text { Block } \\
\text { schedule } \\
\text { ("x } x+y ")\end{array}$ & No & Yes & No \\
\hline $\begin{array}{l}\text { Two } \\
\text { continuity sites }\end{array}$ & No & No & Yes \\
\hline $\begin{array}{l}\text { Longitudinal } \\
\text { long block } \\
\text { (two months } \\
\text { or greater) }\end{array}$ & No & Yes & Yes \\
\hline $\begin{array}{l}\text { Community } \\
\text { versus } \\
\text { Academic } \\
\text { Hospital }\end{array}$ & $\begin{array}{l}\text { Predominantly } \\
\text { academic } \\
\text { hospital with } \\
\text { fraction of } \\
\text { inpatient time at } \\
\text { affiliated } \\
\text { community } \\
\text { hospital }\end{array}$ & $\begin{array}{l}\text { Time evenly } \\
\text { split between } \\
\text { academic } \\
\text { hospital and } \\
\text { community } \\
\text { hospital }\end{array}$ & $\begin{array}{l}\text { Time evenly } \\
\text { split between } \\
\text { academic } \\
\text { hospital and } \\
\text { community } \\
\text { hospital }\end{array}$ \\
\hline
\end{tabular}

*Statistics are for all residents in the programs for the stated years, and include but are not limited to the residents who participated in the study.

"Primary care related" was defined as jobs with any part-time primary care practice, including precepting of residents. "Nonprimary care" was defined as careers in subspecialty medicine (including consultative geriatrics, palliative care and occupational medicine) without any component of longitudinal general medicine, or hospitalist medicine. Program directors were asked to include current chief residents with known future plans in one of these categories.

In addition to assessing career outcomes for graduated residents, a separate survey was sent to all primary care resident graduates from 2012-2014 asking about intent to pursue primary care careers upon entering into residency training. This survey had one question: "As best as you can recall just before you entered residency, what career were you most interested in pursuing after residency?" The above choices of "Full-time primary care," "Primary care related," and "Non-primary care" were listed along with the above descriptions.

Interviews were conducted with second and third year primary care internal medicine residents. We excluded interns, since the timing of their personal career decisions was more distant, and due to their comparatively limited experience in residency. We used a survey guide developed from pilot interviews as well as existing literature. ${ }^{3,4,7-9,18-20}$ Our review of peer reviewed studies revealed that there were several periods of time that may contribute to the decision to enter primary care for a career. These periods were characterized as "path to primary care," "primary care residency experience," and "plans after residency." The questions for each of these periods included factors such as how mentorship or outpatient 
clinic experience may have contributed to a potential change in the decision of the resident to pursue primary care for their career. These questions were reviewed in pilot interviews and feedback was incorporated into the interview survey guide. We used directed content analysis to characterize resident experiences (see Appendix online for a full list of questions). ${ }^{21}$ Verbal consent was obtained from all study participants. Institutional Review Board exemption was obtained from each institution in this study. Precautions were taken to ensure confidentiality, including removal of the demographics data from the transcriptions and review of demographic information only in aggregate by the composed team.

\section{Data Collection}

Two interviewers contacted primary care internal medicine residents at the three sites to enroll them in the study. The interviewers did not have any relationship to the interviewed residents, and each interviewer did not attend the training program where he conducted the interviews. The interviewers were both in the healthcare field, with one being a physician in training and the other being a practicing physician. We invited all residents in each second and third year class to participate as "key informants," 22 given their ability to describe a range of experiences regarding the decision to stay in or leave primary care after residency, as well as to uncover potentially mutable factors on a program level. We interviewed residents from December 2013 to December 2014. Interviews were an average of 45 minutes. Each was audiotaped and professionally transcribed. Interviews were conducted at each site until the analysis team agreed that data saturation was reached at each site.

\section{Analysis}

The analysis was completed by an interdisciplinary team of a health services researcher, a primary care internal medicine chief resident, and a qualitative consultant. These three team members completed the in-depth coding. After initial codes were developed by this interdisciplinary team, the team then met to negotiate consensus and resolve differences in coding. The process was conducted iteratively as interviews continued. The code structure was developed in stages based on grounded theory, ${ }^{15,16}$ using a systematic and inductive approach to generate insights from the views of the study participants. We used the constant comparative method to identify emerging themes and refine codes.

The three members of the interdisciplinary team completed all initial coding. At key points in the analysis, the codes were reviewed and modified by content experts (a primary care program director and an associate program director). As the coding continued, the content experts worked with the interdisciplinary team to refine the final codes. Concurrently, as additional sites were enrolled, a current or former primary care chief resident was brought onto the analysis team to complete coding for each site. The coding from the chief residents was completed alongside the coding of the three members of the interdisciplinary team. This was done to ensure that details about the training experiences for residents or site-specific issues were fully understood by the entire analysis team. The entire analysis team was comprised of the three members of the interdisciplinary coding team, the content experts, and the site-specific chief residents. Once the coding had been completed by the interdisciplinary team as well as the chief residents at each site, the codes were organized into the main themes. We used ATLAS.ti 7.0 (Corvallis, Oregon) for data analysis.

\section{RESULTS}

\section{Sample}

We interviewed 24 primary care internal medicine residents (seven at the site 1, nine at the site 2, and eight at the site 3). Fifty percent were post-graduate year (PGY) 3 , and $50 \%$ were PGY-2 (Table 2). The age range was 27 to 39 years. Fifteen $(62 \%)$ designated that they were definitely planning to go into primary care.

In addition, results from the short survey assessing intent to pursue primary care careers upon entering into primary care residency training are displayed in Table 3 . This survey was sent to all graduated residents from 2012 to 2014 at each site. The response rates for Site 1, Site 2, and Site 3 were $96 \%$, $90 \%$, and $92 \%$, respectively.

\section{Themes}

We identified four recurrent and unifying themes: resident expectations of a career in primary care, navigation of the boundary between social needs and medical needs, mentorship and perceptions of primary care, and structural features of the training program (Table 4).

\section{RESIDENT EXPECTATIONS OF A CAREER IN PRIMARY CARE}

Residents described that they had difficulty imagining practicing full-time primary care after residency. While residents entered training with an expectation of what primary care

Table 2 Characteristics of Participants

\begin{tabular}{ll}
\hline \hline & N (\% of participants) \\
\hline Site 1 & $7(29 \%)$ \\
Site 2 & $9(37 \%)$ \\
Site 3 & $8(33 \%)$ \\
PGY-2 & $12(50 \%)$ \\
PGY-3 & $12(50 \%)$ \\
Age range & $27-39$ \\
Sex & \\
$\quad$ Women & $15(62 \%)$ \\
$\quad$ Men & $9(37 \%)$ \\
Planning a career in primary care? & $15(62 \%)$ \\
\hline
\end{tabular}


Table 3 Primary Care Career Intent

\begin{tabular}{|c|c|c|c|}
\hline & Site 1 & Site 2 & Site 3 \\
\hline & $\begin{array}{l}\mathbf{N}(\% \text { of } \\
\text { graduates) }\end{array}$ & $\begin{array}{l}\mathbf{N}(\% \text { of } \\
\text { graduates })\end{array}$ & $\begin{array}{l}\mathbf{N}(\% \text { of } \\
\text { graduates })\end{array}$ \\
\hline $\begin{array}{l}\text { "Full-time } \\
\text { primary care" }\end{array}$ & $1(4 \%)$ & $7(19 \%)$ & $6(25 \%)$ \\
\hline $\begin{array}{l}\text { "Primary care } \\
\text { related" }\end{array}$ & $21(84 \%)$ & $19(51 \%)$ & $18(75 \%)$ \\
\hline $\begin{array}{l}\text { "Non-primary } \\
\text { care" }\end{array}$ & $3(12 \%)$ & $11(30 \%)$ & $0(0 \%)$ \\
\hline
\end{tabular}

practice would be like, these expectations changed during their training. Two subthemes characterize the nature of the change in their expectations. First, their interactions with practicing primary care physicians gave them insight into the challenges of practice, raising concerns over burn out if they pursued a similar path. Second, residents described mismatched expectations between the ideals of primary care practice with which they came into residency and the real-world challenges of primary care practice that they witnessed.

\section{Concern Over the Challenges of Primary Care Practice and Burn Out}

As one resident explained, some faculty members regard fulltime clinical practice as excessively onerous and not feasible to sustain.

We have a set of 15 or 20 core faculty in our primary care residency program. All of them love their lives and their jobs. None of them practice primary care fulltime. If you press them on it, the idea of doing five full days of primary care a week not only makes them start to hate their lives just thinking about it, but they don't think it's possible to do that. They're either on board for joining the defeat and going down with the ship or

Table 4 Themes Across All Sites

\begin{tabular}{|c|c|}
\hline Main Themes & Subthemes \\
\hline $\begin{array}{l}\text { Resident expectations of a career } \\
\text { in primary care }\end{array}$ & $\begin{array}{l}\text { Concern over the challenges of } \\
\text { primary care practice and burn } \\
\text { out } \\
\text { Mismatched expectations }\end{array}$ \\
\hline $\begin{array}{l}\text { Navigation of the boundary } \\
\text { between social needs and medical } \\
\text { needs }\end{array}$ & $\begin{array}{l}\text { Feeling ill-equipped to address } \\
\text { social needs } \\
\text { Need for behavioral health } \\
\text { integration } \\
\text { Need for more resources to } \\
\text { address social needs }\end{array}$ \\
\hline $\begin{array}{l}\text { Mentorship and perceptions of } \\
\text { primary care }\end{array}$ & $\begin{array}{l}\text { Mentors and role models within } \\
\text { program } \\
\text { Supportive peer group } \\
\text { Institutional perceptions of } \\
\text { primary care }\end{array}$ \\
\hline $\begin{array}{l}\text { Structural features of the training } \\
\text { program }\end{array}$ & $\begin{array}{l}\text { Variety of outpatient experiences } \\
\text { Amount of dedicated outpatient } \\
\text { time } \\
\text { Desire for a cohesive primary } \\
\text { care curriculum }\end{array}$ \\
\hline
\end{tabular}

finding some hybrid career where they can do some primary care well.

\section{Mismatched Expectations}

Other residents were surprised by the challenges of primary care practice as experienced in residency. Residents stated that they knew before residency that there were certain compromises inherent in primary care, such as a lower salary. However, they did not anticipate the stress and fear of burn out that they experienced.

I was okay with the fact that making over $\$ 100,000$ puts me in an average category, [but] there are other factors as far as life stress and fear of burning out that are more negative, like not being able to practice how I would want to practice. I always felt like I would rather work somewhere where I felt like: this is idealistic but you could provide the right care without having to feel overly stressed about are you turning a profit.

\section{NAVIGATION OF THE BOUNDARY BETWEEN SOCIAL NEEDS AND MEDICAL NEEDS}

Residents cited the complex relationship between social and medical needs of patients in the primary care setting. While many residents described an interest in caring for the underserved, they also noted barriers to delivering the care they had envisioned based on the high degree of social needs among their patients. The theme had three subthemes. First, residents noted frustration with an inability to address social needs. Second, residents desired integration of primary care with behavioral health and social services. Third, residents described needing more administrative support in their clinics to address the complex social needs of patients.

\section{Feeling III-equipped to Address Social Needs}

One resident explained how the social needs of patients had a substantial impact on their medical treatment, and while acknowledging the importance of addressing those social needs, did not feel capable of solving the systemic problems impacting her patients' health.

I don't know how to get somebody who has lost their heat their heat back on. She's not going to come to her medical appointment if she's bogged down in that kind of thing. In winter, she needs to have heat. I don't know how to solve that problem for her. I'm not trained to do that. 
A resident observed that responding adequately to social needs, which are often the most important issues to patients, can be overwhelming in the primary care setting.

The last question he asked me when he came into the clinic was, "Do you have any clothes?" You not only deal with the medicine aspect, you deal with all the psychosocial stuff-patients who are in real dire need. It's just like an added extra to the already incredible demands on you in the outpatient setting.

Another resident brought up concern over burn out from the challenges of trying to address social care needs, which often have no solution:

One of the frustrations that I've had is that our clinic is so under-resourced that I've found it's difficult to provide the care that I thought I'd be able to provide. I thought that most of my focus would be on relationship, on their medical issues, but I spend so much of my time trying to triage things through a piece of paper trying to get access to social services that don't exist. When you don't have the resources, it's hard to continue to envision a future that looks like that without getting burnt out.

\section{Need for Behavioral Health integration}

Residents identified comprehensive behavioral health as necessary to patient care and expressed frustration that these services are not more accessible.

A lot of the stuff that I'm doing for my patients is stuff that could be done by other providers working in a team, but we don't really have those providers. We have a mental health provider that sees patients once a week. We have a behavioral change psychologist who sees patients once a week. Those are good resources, but I think a lot of our patients have social needs that could be benefitted from having a social worker.

\section{Need for More Resources to Address Social Needs}

Residents also described that they felt they needed more administrative support in clinic to assist with timeintensive tasks pertaining to patients' social needs, such as disability paperwork. One resident explained:

Sometimes I spend just as much time in the clinic session wrapping up notes and doing disability paperwork or other kind of administrative stuff as seeing patients. Having built in administrative time I think is a way to avoid that. Trying to choose a more functional clinic is just going to be part of my job search.

\section{MENTORSHIP AND PERCEPTIONS OF PRIMARY CARE}

Residents described that they felt encouraged by positive relationships with mentors and having a supportive peer group and discouraged when they encountered faculty or peers who expressed a negative perception of primary care. Three subthemes arose from this theme. First, residents described the inspiration of having esteemed mentors. Second, residents noted that despite the stress of residency, having a positive peer group kept them motivated. Third, residents explained that negative perceptions of primary care, such as a lack of prestige, were often expressed by the broader institutional faculty or peers in other programs during their training.

\section{Mentors and Role Models within Program}

One resident described that she was inspired by her mentor's relationship with her patients.

Spending time with my mentor has really reinforced my love for primary care. She is really the model of an excellent primary care physician. She loves her patients. They adore her. She sees generations of families. Just the adoration and the respect and the honor that they have I see that and I think that is so precious.

\section{Supportive Peer Group}

Residents described support among their peers, with one describing how the culture of the program inspired a supportive peer group.

I never feel like I can throw in the towel [on primary care] when I'm around my peers. All the other residents and interns are so amazing and so inspiring that I think it has to start with them, because then they make a great colleague and then they make great chief residents and then great faculty and then the cycle continues. I think it is in the culture here.

\section{Institutional Perceptions of Primary Care}

Residents noted that there was a cultural sense that primary care lacked the prestige of other medical fields. One resident described this by saying:

I think the general feeling is that obviously there is the unfortunate hidden curriculum in medical school, where people feel like there is not as much prestige in primary care. People, even in other fields at this institution, have been like-'you're doing general medicine?' 


\section{STRUCTURAL FEATURES OF THE TRAINING PROGRAM}

Several structural aspects of training were brought up by residents as relevant to their experience. Some residents linked these features with the decision to enter primary care for their careers. Three subthemes characterized how to improve training. First, residents stated that exposure to a variety of outpatient experiences enhanced both their learning and their perceptions of primary care. Second, residents reported that a greater amount of time dedicated to primary care would enhance their proficiency and comfort with outpatient medicine. Third, residents noted greater satisfaction when there was cohesiveness in the ambulatory curricula.

\section{Variety of Outpatient Experiences}

One resident explained that experiences in other primary care settings, often that were functioning at a higher level than the resident clinic, was something that was greatly appreciated. The opportunity to see other practices had a positive impact on residents choosing to stay in primary care after residency.

I'm grateful that I have other experiences in primary care. We have outpatient blocks at private offices so I've seen many other different models of care and if I didn't I think I'd be in trouble. Which is why I think so many other residents don't like primary care because they don't see anything else [except one continuity clinic].

\section{Amount of Dedicated Outpatient Time}

Residents noted that the balance was tilted toward inpatient training, and that more time in primary care would raise their comfort in providing primary care after residency training.

We spend way more time in the hospital than we do out of the hospital, despite being in a primary care program. I think, in order to really train us, we need to spend the time that we spend inpatient on outpatient. I feel like if I took a hospitalist job I have my flow, I know how to do this, I was taught how to do this by my residency program. But I don't have that same kind of comfort level with outpatient medicine, and that's what I want to do.

\section{Desire for a Cohesive Primary Care Curriculum}

Residents finally described seeing value in having a cohesive didactic curriculum that was linked to their primary care training. One resident said:

The curriculum is quite a masterpiece. They took the one-hundred twenty most commonly-encountered disease processes or issues in medicine and found one or two relevant articles related to them. All I have to do is really just read it.

\section{DISCUSSION}

In this multi-site qualitative study, residents identified attributes of their training that may negatively or positively impact their decision to pursue a career in primary care. These attributes were programmatic and contextual factors that were understood as domains and constructs through a grounded theory approach. On the negative side, residents noted a lack of role models successfully practicing primary care full-time, feeling inadequately trained in primary care with disproportionately low outpatient time, and feeling frustrated and at times burned out by trying to deal with the substantial social needs of their underserved clinic population, which they did not expect upon entering residency. Positive reflections included supportive mentorship, and for some, the opportunity to see a variety of outpatient clinical experiences that exposed them to examples of high-functioning primary care practices as positive attributes of training. As we continue to face a looming primary care shortage in the US, primary care training programs should seek to address the areas that our study participants identified as barriers to careers in primary care.

Our results contribute to the understanding of how the training experience of primary care residents affects their satisfaction and ultimately their career choices. Former studies have examined the association between clinic operations and resident satisfaction, demonstrating a correlation with the value residents place on continuity clnic. ${ }^{7,9}$ Improving clinic function through moving toward a patient-centered medical home $(\mathrm{PCMH})$ has also been shown to be associated with increased resident satisfaction with their clinical experience. ${ }^{7}$ Our findings demonstrate areas for potential program-level intervention within the resident clinic experience. Three areas that could be addressed are improved function of the resident clinic, dedicated and varied outpatient experiences with increased volume of primary care training, and greater discussion of the challenges of practicing primary care, balancing the joys and rewards with the frustration and stressors.

Residents described that the function and resources in their clinics were inadequate to successfully manage their patients' social needs, which residents perceived as directly impacting their medical care. Enhancing primary care delivery has been the goal of models such as the PCMH, which includes a teambased approach to primary care delivery. ${ }^{23}$ As Hochman et al. showed, moving toward a PCMH model in a safety-net clinic staffed by residents improved the satisfaction of both residents and patients. ${ }^{7}$ Achieving the goals of the PCMH model may be especially relevant for resident clinics, ${ }^{24,25}$ as clinical practice redesign may positively impact resident training and satisfaction with their clinical experience. Residents who had spent time in higher functioning primary care clinics, which included PCMHs, valued the exposure to these types of 
practice models. As the field of medicine begins to move from volume to value-based care that includes delivery system models such as PCMH, the effect of this change on resident choices should have continued evaluation.

Residents desired more outpatient clinical time to prepare them for practice. In an effort to capture a breadth of resident experiences, we included different structural characteristics of the training programs as part of our site selection, such as variation in presence of an " $x+y$ " block schedule and ambulatory long block. A proposed strategy to address the need for more continuous outpatient training has been to create a block scheduling structure with alternating inpatient and outpatient blocks; during outpatient blocks residents are exclusively in their continuity clinic for a number of consecutive weeks. ${ }^{26}$ Another example of immersion in the ambulatory setting is the ambulatory long block, during which residents spend 12 months in the primary care setting between second and third year of residency. ${ }^{27} \mathrm{~A}$ cross-sectional study of 12 institutions participating in the Educational Innovations Project Ambulatory Collaborative showed that block models with clear separation between inpatient and outpatient experiences minimized conflict across care settings. ${ }^{28}$ While these results are promising, we found that residents highly valued other structural characteristics of training programs. Residents in our study consistently brought up the importance of spending time in other clinical sites where they had the opportunity to see high-functioning practices. Facilitating exposure to a variety of outpatient experiences may enhance residents' experience of outpatient medicine.

Finally, residents described that due to their experiences in clinic during residency and due to a lack of role models who practiced primary care full-time, they had difficulty envisioning themselves in primary care for their careers. The importance and value of mentorship is something that is being increasingly appreciated in medicine. ${ }^{29-31}$ Mentors and primary care faculty in different training sites will have multiple aspects to their jobs, and additional exposure to full-time primary care physicians may help to give residents a more complete understanding of what a fulltime career in primary care might entail for them. Conversely, depending on the goals of the program, continued exposure to part-time faculty could offer an alternative to full-time practice for residents who are considering other aspects of their careers such as research or administration.

Our study has several limitations. First, the qualitative design does not allow for generalizability of the findings. However, the design is well suited for hypothesis generation, and the prospective selection of three sites with variation in program characteristics afforded a breadth of resident experiences. Second, residents not choosing primary care careers may feel that their viewpoints are less palatable, and therefore may have self-selected out of the study. In other cases, residents may have felt that raising their opinions may have been challenging, and may have not contributed their full opinions. However, among the residents approached to participate, no residents declined to be in the study. Third, all sites in the study were affiliated with academic medical centers, and residents training solely in community hospitals may have a different experience. We did, though, include programs with varying exposure to community hospitals in an effort to have a variety of experiences from the residents interviewed. Fourth, our study focused on primary care internal medicine residents, and did not explore factors contributing to other primary care residents, such as those in family medicine, choosing to stay in primary care for their careers. This would be a potentially important direction for future evaluation, to ensure that each primary care specialty has an appropriate level of understanding in terms of factors that could be addressed to improve retention in primary care.

In this qualitative study, residents identified potentially modifiable aspects of residency training that if addressed may lead to an increase in the percentage of residents who choose to pursue careers in primary care. These include providing access to professionally satisfied role models who practice full-time primary care in addition to academic primary care physicians; garnering resources to address the high psychosocial burden of patients cared for in resident continuity clinics; expanding, enhancing, and diversifying the ambulatory training experiences; and addressing local cultural issues regarding the value and prestige of primary care in the sponsoring institution. Further inquiry with a longitudinal evaluation of career decisions over time and associations with identified contributing factors could enhance our understanding of interventions to consider. The themes identified in this qualitative study may be helpful to program development of primary care training programs, with further research focused on which of the modifiable aspects of residency training are associated with greater retention of primary care residents in primary care career paths.

\section{Acknowledgements:}

Funders: This work received financial support from the Robert Wood Johnson Foundation through the Yale Robert Wood Johnson Clinical Scholars Program.

Prior Presentations: An abstract for this manuscript was presented at the Northeast Regional meeting of the Society of General Internal Medicine as an oral presentation and at the national meeting of the Society of General Internal Medicine as a poster presentation.

Corresponding Author: Theodore Long, MD MHS; Robert Wood Johnson Clinical Scholars ProgramYale School of Medicine, 333 Cedar Street, SHM IE-61, PO Box 208088, New Haven, CT 06520, USA (e-mail: theodore.long@yale.edu).

\section{Compliance with Ethical Standards:}

Funding Sources: None.

Conflicts of Interest: The authors declare that they do not have a conflict of interest. 


\section{REFERENCES}

1. Colleges AAM. The Complexities of Physician Supply and Demand: Projections from 2013 to 2025. Washington, D.C.: IHS, Inc.; 2015.

2. West CP, Dupras DM. General medicine vs. subspecialty career plans among internal medicine residents. JAMA : J Am Med Assoc. 2012;308(21):2241-2247.

3. Fox M. Medical student indebtedness and the propensity to enter academic medicine. Health Econ. 2003;12(2):101-112.

4. Tardiff K, Cella D, Seiferth C, Perry S. Selection and change of specialties by medical school graduates. J Med Educ. 1986;61(10):790-796.

5. Robert Graham Center. What influences student \& resident choices? 2009; http://www.graham-center.org/dam/rgc/documents/publications-reports/monographs-books/Specialty-geography-compressed.pdf. Accessed July 3, 2016.

6. McPake B, Squires A, Mahat A, Araujo E. Economics of health professional education and careers : insights from a literature review. Washington, DC: World Bank Group; 2015

7. Sisson SD, Boonyasai R, Baker-Genaw $\mathbf{K}$, Silverstein J. Continuity clinic satisfaction and valuation in residency training. $J$ Gen Intern Med. 2007;22(12): 1704-1710.

8. Weaver SP, Mills TL, Passmore C. Job satisfaction of family practice residents. Fam Med. 2001;33(9):678-682.

9. Hochman ME, Asch S, Jibilian A, et al. Patient-centered medical home intervention at an internal medicine resident safety-net clinic. JAMA Intern Med. 2013.

10. Chaudhry SI, Balwan S, Friedman KA, et al. Moving forward in GME reform: a 4+1 model of resident ambulatory training. J Gen Intern Med 2013;28(8):1100-1104.

11. Stanley M, O'Brien B, Julian $\mathbf{K}$, et al. Is training in a primary care internal medicine residency associated with a career in primary care medicine? J Gen Intern Med. 2015;30(9):1333-1338.

12. Connelly MT, Sullivan AM, Peters AS, et al. Variation in predictors of primary care career choice by year and stage of training. J Gen Intern Med 2003;18(3):159-169.

13. Choi PA, Xu S, Ayanian JZ. Primary care careers among recent graduates of research-intensive private and public medical schools. J Gen Intern Med. 2013;28(6):787-792.

14. Erikson CE, Danish S, Jones KC, Sandberg SF, Carle AC. The role of medical school culture in primary care career choice. Acad Med. 2013;88(12):1919-1926.

15. Charmaz K. Constructing Grounded Theory. London: Thousand Oaks, Calif.: Sage Publications; 2006.

16. Glaser BG, Strauss AL. The discovery of grounded theory; strategies for qualitative research. Chicago: Aldine Pub. Co.; 1967.
17. Hodkinson P, Andrew C. Sparks. Careership: a sociological theory of career decision making. Br J Sociol Educ. 1997;18(1):29-44.

18. Witzburg RA, Noble J. Career development among residents completing primary care and traditional residencies in medicine at the Boston City Hospital, 1974-1983. J Gen Intern Med. 1988;3(1):48-53.

19. Weil PA, Schleiter MK. National Study of Internal Medicine Manpower: VI. Factors predicting preferences of residents for careers in primary care or subspecialty care and clinical practice of academic medicine. Ann Intern Med. 1981;94(5):691-703.

20. Julian K, Riegels NS, Baron RB. Perspective: Creating the next generation of general internists: a call for medical education reform. Acad Med : J Assoc Am Med Coll. 2011;86(11):1443-1447.

21. Hsieh HF, Shannon SE. Three approaches to qualitative content analysis Qual Health Res. 2005;15(9): 1277-1288.

22. Mays $\mathbf{N}$, Pope C. Rigour and qualitative research. BMJ. 1995;311(6997):109-112.

23. Guidelines for Patient-Centered Medical Home (PCMH) Recognition and Accreditation Programs. https://www.acponline.org/system/files/documents/running_practice/delivery_and_payment_models/pcmh/understanding/guidelines_pcmh.pdf. Accessed July 3, 2016.

24. David A, Baxley L. Adfm. Education of students and residents in Patient Centered Medical Home (PCMH): preparing the way. Ann Fam Med. 2011;9(3):274-275.

25. Chang A, Bowen JL, Buranosky RA, et al. Transforming primary care training-patient-centered medical home entrustable professional activities for internal medicine residents. J Gen Intern Med. 2013;28(6):801-809.

26. Colbert JA. Experiments in continuity-rethinking residency training in ambulatory care. N Engl J Med. 2013;369(6):504-505

27. Warm EJ, Schauer DP, Diers T, et al. The ambulatory long-block: an accreditation council for graduate medical education (ACGME) educational innovations project (EIP). J Gen Intern Med. 2008;23(7):921-926.

28. Francis MD, Thomas $\mathbf{K}$, Langan $\mathbf{M}$, et al. Clinic design, key practice metrics, and resident satisfaction in internal medicine continuity clinics: findings of the educational innovations project ambulatory collaborative. $\mathrm{J}$ Grad Med Educ. 2014;6(2):249-255.

29. Blanchard RD, Visintainer PF, La Rochelle J. Cultivating Medical Education Research Mentorship as a Pathway Towards High Quality Medical Education Research. J Gen Intern Med. 2015;30(9):1359-1362.

30. Dhami G, Gao W, Gensheimer MF, Trister AD, Kane G, Zeng J. Mentorship programs in radiation oncology residency training programs: a critical unmet need. Int J Radiat Oncol Biol Phys. 2016;94(1):27-30.

31. Kost A, Benedict J, Andrilla CH, Osborn J, Dobie SA. Primary care residency choice and participation in an extracurricular longitudinal medical school program to promote practice with medically underserved populations. Acad Med. 2014;89(1):162-168. 